Canadian Journal of Applied Linguistics

Revue canadienne de linguistique appliquée

\title{
Innovation and Reform in Course Planning, Teaching, and Assessment: The CEFR in Canada and Switzerland, A Comparative Study
}

\author{
Enrica Piccardo, Brian North and Eleonora Maldina
}

Volume 22, Number 1, 2019

Special Issue: In Memory of Larry Vandergrift

Numéro spécial : à la mémoire de Larry Vandergrift

URI: https://id.erudit.org/iderudit/1060908ar

DOI: https://doi.org/10.7202/1060908ar

See table of contents

Publisher(s)

University of New Brunswick

ISSN

1920-1818 (digital)

Explore this journal

Cite this article

Piccardo, E., North, B. \& Maldina, E. (2019). Innovation and Reform in Course Planning, Teaching, and Assessment: The CEFR in Canada and Switzerland, A Comparative Study. Canadian Journal of Applied Linguistics / Revue canadienne de linguistique appliquée, 22(1). https://doi.org/10.7202/1060908ar

\section{Article abstract}

Change and innovation in education require carefully thought-through procedures as well as time, and benefit both from exchanges of expertise between contexts and from quality assurance (QA) processes. A key document that stimulates change in planning, teaching, and assessment is the Council of Europe's (2001) Common European Framework of Reference for Languages (CEFR). However, its innovation potential in language education has been affected by a lack of impact studies and QA procedures. This article reports on the QualiCEFR study, which aims to encourage a culture of QA in relation to planning, teaching, and assessment and to identify promising practices in those processes. The study compared CEFR implementation in Switzerland and Canada employing a mixed-methods design and a QA approach, thematically analyzing data from over 40 interviews. Results have helped to inform the development of an online tool produced in a sister project of the European Centre for Modern Languages (ECML).
Copyright (c) Enrica Piccardo, Brian North, Eleonora Maldina, 2019

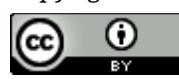

This document is protected by copyright law. Use of the services of Érudit (including reproduction) is subject to its terms and conditions, which can be viewed online.

https://apropos.erudit.org/en/users/policy-on-use/ 


\title{
Innovation and Reform in Course Planning, Teaching, and Assessment: The CEFR in Canada and Switzerland, A Comparative Study
}

\author{
Enrica Piccardo \\ OISE-University of Toronto \\ Brian North \\ Eurocentres Foundation \\ Eleonora Maldina \\ OISE-University of Toronto
}

\begin{abstract}
Change and innovation in education require carefully thought-through procedures as well as time, and benefit both from exchanges of expertise between contexts and from quality assurance (QA) processes. A key document that stimulates change in planning, teaching, and assessment is the Council of Europe's (2001) Common European Framework of Reference for Languages (CEFR). However, its innovation potential in language education has been affected by a lack of impact studies and QA procedures. This article reports on the QualiCEFR study, which aims to encourage a culture of QA in relation to planning, teaching, and assessment and to identify promising practices in those processes. The study compared CEFR implementation in Switzerland and Canada employing a mixed-methods design and a QA approach, thematically analyzing data from over 40 interviews. Results have helped to inform the development of an online tool produced in a sister project of the European Centre for Modern Languages (ECML).
\end{abstract}

\section{Résumé}

Le changement et l'innovation en éducation nécessitent à la fois du temps et des procédures soigneusement réfléchies. Tous deux bénéficient aussi d'échanges d'expertise entre différents contextes ainsi que de processus d'assurance de la qualité (AQ). Le Cadre européen commun de référence pour les langues (CECR) est un document clé qui est en mesure de stimuler le changement au niveau de la planification, de l'enseignement et de l'évaluation (Conseil de l'Europe, 2001). Néanmoins, son potentiel d'innovation dans l'enseignement des langues a souffert du manque d'études sur les incidences du CECR et de procédures d'AQ. Cet article rend compte de l'étude QualiCEFR, dont le but était d'encourager une culture d'AQ dans les processus de planification, d'enseignement et d'évaluation ainsi que d'identifier de bonnes pratiques dans ces mêmes processus. En utilisant un modèle multiméthodes et une approche d'AQ, l'étude a comparé la mise en œuvre du CECR en Suisse et au Canada à travers une analyse thématique de données provenant de plus de 40 entrevues. Les résultats ont fourni une base de départ pour le développement d'un outil en ligne produit au cours d'un projet parallèle du Centre européen des langues vivantes (CELV). 


\section{Innovation and Reform in Course Planning, Teaching, and Assessment: The CEFR in Canada and Switzerland, A Comparative Study}

\section{Background to the Project: Potential and Issues of CEFR Implementation}

The Common European Framework of Reference for Languages (CEFR, Council of Europe, 2001), with its origins in the work of the Council of Europe since the 1970s, is a language policy document that was developed to serve as a comprehensive, transparent, and coherent tool to

a) define levels of language competence in terms of practical real-world proficiency,

b) encourage educational reform, and

c) facilitate coherence between curricula, teaching practices, and assessment.

The CEFR puts forward a rich, complex, multidimensional descriptive scheme to define aspects of language proficiency as

a) general competences,

b) communicative language competences, and

c) communicative language activities and strategies,

which are organized according to four modes of communication: reception, production, interaction, and mediation. These modes are in lieu of the traditional four skills. Aspects of the scheme are defined in descriptor scales (50 in 2001, 80 in 2018) in terms of what can be expected at the different proficiency levels. Users can consult these descriptors when analyzing needs and when ensuring constructive alignment (Biggs \& Tang, 2011) between planning, teaching, and assessment. In addition, the CEFR model introduces several significant concepts to language education (i.e., user/learner as social agent, action-oriented pedagogy, mediation, and plurilingualism). The CEFR is recognized as one of the most significant recent developments in second language education in terms of seeing curriculum as a dynamic process (Graves, 2008), employing backward design (i.e., working backwards from learner needs identified as can-do descriptors, Richards, 2013) and encouraging ongoing adjustment during implementation. The way the CEFR has increasingly informed pedagogy and assessment practices in many countries has been documented by Byram and Parmenter (2012).

As the recently-published CEFR Companion Volume with New Descriptors (Council of Europe, 2018) has shown, and as Piccardo and North (2019) explained in more detail, the CEFR vision is at the spearhead of curriculum design (e.g., Graves, 2008). However, implementation of the CEFR is a complex process. For instance, Evaluation and Assessment of Quality Language Services (Eaquals, www.eaquals.org) case studies have suggested that achieving just alignment of curriculum objectives to the CEFR, without necessarily changing the pedagogical approach itself, typically takes successive attempts over several years, as reflection of the initial changes introduced leads to further changes (Eaquals, 2008). In fact, very few CEFR feasibility or impact studies have been undertaken even though the word impact appears in the titles of some studies (e.g., Figueras, 2012; Jones \& Saville, 2009; North, 2010). What does exist are collations of two questionnaires sent by the Council of Europe to the education ministries of member states about the effect 
of the CEFR (Martyniuk \& Noyons, 2007) and of the European Language Portfolio (ELP) [Stoicheva, Hughes, \& Speitz, 2009] — often referred to simply as the Portfolio - and two collections of interesting but anecdotal commentaries by invited contributors from around the world (Byram \& Parmenter, 2012; Piccardo, 2006). Also found are some studies of teachers' reactions to the CEFR (Spain: Díez-Bedmar \& Byram, 2018; Figueras, 2013; Netherlands: Moonen, Stoutjesdijk, de Graaf, \& Corda, 2013) and some reflections on developments in certain countries (e.g., Takala, 2013, on Finland). For Switzerland, the birthplace of the CEFR, there are no publications at all related to CEFR impact. The result of the limited research in this area is a lack of transfer of expertise and inconsistencies in the interpretation of what is conceptually a very complex vision. This, in turn, reduces the benefits of the CEFR in terms of innovation in language policy and classroom pedagogy.

\section{The CEFR in Canada: A Growing Interest}

Canada's first policy-related interest in the CEFR was in Vandergrift's (2006) report, part of the Official Languages Research and Dissemination Program (2004-2005). Vandergrift recommended adopting a common framework for languages across Canada that would provide a common basis for curricula and assessment, and identified the CEFR as the most appropriate model to follow. He cited in particular its construct validity (i.e., the level descriptors are based on a theory of communicative competence and empirically validated); its face validity (i.e., the level descriptors take into account teachers' perceptions and experiences rather than represent "ivory tower" constructs); and its contextual validity (i.e., the branching approach to both levels and categories seemingly accommodate the pedagogical cultures of the different Canadian provinces and territories). He also made suggestions about practical steps that Canada and its provinces and territories could take to proceed with the possible adoption of the CEFR. A few years later, in 2010, the Council of the Ministers of Education of Canada (CMEC) proposed that the CEFR be the reference tool used in the Canadian context (CMEC, 2010), a suggestion supported subsequently by the 2015 Senate Report on Official Languages in Canada (Tardif \& Fortin-Duplessis, 2015).

As a result, the CEFR has since informed the revision of K-12 language curricula in several provinces. Indeed, there have been a number of CEFR-related initiatives in Canada, summarized in detail in Arnott et al. (2017), who stated that "the introduction of the CEFR in the Canadian context sets a positive process in motion at the level of (re)conceptualization of tools and frameworks related to assessment, curriculum, and pedagogy" (p. 33). In Ontario, the CEFR has informed the French as a second language (FSL) curriculum (Ontario Ministry of Education, 2013, 2014) and resources to assist stakeholders in the implementation of the CEFR. In the Atlantic provinces the Conseil atlantique des ministres de l'Éducation et de la Formation (CAMET) is developing a common FSL curriculum that aligns with the CEFR (CAMET, 2010), and in Saskatchewan the Ministry of Education produced a CEFR-informed common framework for English as a second language (ESL) teaching (Saskatchewan Ministry of Education, 2013). Finally, the mobilization of knowledge about the CEFR is a core activity of the Canadian Association of Second Language Teachers (CASLT).

A series of studies (including Faez, Majhanovich, Taylor, Smith, \& Crowley (2011); Kristmanson, Lafargue, \& Culligan, 2011; Mison \& Jang, 2011; Piccardo, 2013) have suggested that Canadian educators recognize the potential of the CEFR, and that 
several of their priorities could be addressed by implementing it. For example, Faez, Majhanovich et al. (2011) after a survey of 93 FSL teachers stated that "teachers reported that CEFR-informed instruction increased student motivation, built self-confidence in their learners, promoted authentic language use in the classroom and encouraged learner autonomy" (p. 1). While some initiatives have focused on the Portfolio (e.g., Beaudoin, 2010; Kristmanson et al., 2011; Rehorick \& Lafargue, 2005), others (e.g., Faez, Taylor, Majhanovich, Brown, \& Smith, 2011) have focused on the pedagogical implications of the CEFR's action-oriented approach through task/projects (Lions-Olivieri \& Liria, 2009; Piccardo \& North, 2019; Puren, 2002, 2009) or on the positive washback effects of introducing the Diplôme d'études en langue française (DELF) examination for FSL (e.g., Ottawa-Carleton District School Board, 2010, 2011; Rehner, 2014; Tang, 2010). Studies in Ontario (Faez, Majhanovich et al., 2011; Faez, Taylor et al., 2011; Majhanovich, Faez, Smith, Taylor, \& Vandergrift, 2010) have led to an adoption in the province of the CEFR's holistic approach to curriculum, teaching, and assessment with the development, from 2013 onwards, of online support for teachers (see www.transformingfsl.ca and https://sites.google.com/teltgafe.com/cefr-ontario).

In 2014, a discussion forum of 24 researchers from six provinces held in St. Catharines, Ontario outlined possible pathways for further Canadian engagement with the CEFR. Responding to a widely held view at that event

that teachers lack a broad-enough understanding of the CEFR to introduce (aspects of) its use in their teaching and assessment practices . . the Ontario Ministry of Education funded a project that ... [engaged] ... teachers in a semester-long professional development opportunity, combining training on the concepts underpinning the CEFR and development of both conceptual and pedagogical resources. (Arnott et al., 2017, p. 36)

Readers are referred to Arnott et al. (2017) for a more detailed overview of these initiatives and research results.

Finally, a focus group study with participants from six provinces stated that:

findings show that Canadian stakeholders see CEFR as a strength of FSL programs, with potential to inform assessment and pedagogy. Participants also reported that working with CEFR could address other central issues that were raised repeatedly: developing speaking proficiency, providing relevant professional development to teachers, providing a direction for resource development, and so on. (CMEC, 2015, p. 11)

The study also reported that "participants expressed great interest in communicating and collaborating across jurisdictions on initiatives they were undertaking to adapt CEFR/DELF to the Canadian context" (CMEC, 2015, p. 12).

\section{The QualiCEFR Project: Rationale and Aims}

Considering the situation described above, and with a widespread interest in the CEFR and a wealth of initiatives on the one hand and a lack of systematic implementation based on solid principles on the other, the QualiCEFR research project, funded by the 
Social Science and Humanities Research Council (SSHRC), has been conducted to build on current experience with the CEFR in Canada and Switzerland in order to facilitate the transfer of CEFR-related knowledge and know-how and to support CEFR implementation informed by quality assurance (QA) concepts and procedures. More broadly, QualiCEFR aims to identify and promote successful CEFR implementation strategies, encourage a culture of evidence-based QA in CEFR implementation, and stimulate reflection about the key challenges and benefits for language education that the CEFR brings.

The choice to study Canada and Switzerland is related to some of their similarities and differences. Both are decentralized, multilingual countries with high rates of immigration ${ }^{1}$ in which responsibility for education is delegated to provinces/territories and cantons respectively. Switzerland played a leading role in conceptualizing the CEFR and has been actively implementing it since 1996, whereas Canada engaged with the CEFR approximately 10 years after Switzerland's adoption as outlined above. In fact, the very idea of a common framework for language learning and a related language portfolio to report progress were both Swiss proposals, recommended by an intergovernmental Symposium held near Zurich in 1991 (Council of Europe, 1992). The descriptors for the CEFR and the prototype ELP were developed and validated in a Swiss National Research Council project (North, 1995, 2000; North \& Schneider, 1998; Schneider \& North, 2000). Appropriate CEFR levels were suggested for different target languages in each educational sector (Schweizerische Konferenz der kantonalen Erziehungsdirektoren [EDK], 1998), and made mandatory in a Swiss national strategy (EDK, 2004). Following this, more detailed CEFR-related national educational standards were introduced in a project called HarmoS (Lenz, 2007; Ramseier, Moser, Moreau, \& Antonietti, 2008). Indeed, it is interesting to highlight that the Swiss authorities were consulted by the Canadian Senate Committee on Official Languages and their insights appear in the 2015 Senate Report mentioned above (Tardif \& Fortin-Duplessis, 2015).

\section{Theoretical Framework}

The QualiCEFR project draws on methods used in QA, program evaluation, and impact studies in order to investigate and inform the process of implementing the CEFR. QA has been applied in schemes developed specifically for language education (e.g., Eaquals, Accreditation UK, NEAS in Australia, Label FLE in France). Such schemes often involve the analysis of curricula, resources, and processes in an inspection of planning, teaching, and assessment practices (Heyworth, 2013; Muresan, Heyworth, Mateva, \& Rose, 2007). A typical QA scheme in language education includes self-assessment questionnaires, analyses of documents and resources, interviews with key staff, focus groups including teachers and students, classroom observations, and systematic evaluation in relation to defined quality standards (Matheidesz, 2010).

Program evaluation and impact studies are two other approaches to the investigation of quality in education. The program evaluation approach has been associated with particular language for specific purposes projects, and remains relevant today (Kiely \& Rea-Dickins, 2005). However, impact studies have become more common, particularly in relation to standardized tests and the desirable and undesirable effects on teaching (i.e., washback) that such tests cause. Impact studies in language education tend to include 
a) analyzing curriculum documents, textbooks, and tests,

b) interviewing staff/teachers/students, and

c) conducting surveys.

Although the vast majority of impact studies in the language field investigate the washback effect from high-stakes language tests (e.g., Hawkey, 2006; Rea-Dickins \& Scott, 2007; Wall, 2012), studies also take place in mainstream educational contexts (e.g. Dickinson, 2011; Gamse, Bloom, Kemple, \& Jacob, 2008). The decision to draw upon a theoretical framework that aligns with QA-informed approaches is prompted by the lack of this type of study and by the appropriateness of this particular framework for the implementation of the CEFR, which is usually a relatively complex and lengthy process in terms of curriculum design and a reform of pedagogy and assessment.

\section{Research Questions and Methodology Used}

The QualiCEFR study addressed the following research questions:

1. What procedures were used to introduce the implementation of the CEFR in different educational contexts in Canada and Switzerland? This is a factual record of the modalities and procedures followed in exploiting aspects of the CEFR.

2. Has a QA approach (or elements thereof) informed CEFR implementation? Since neither country concerned has a dedicated QA scheme for state education, the aim was to see if QA elements were found in the planning of the projects reported on.

3. What CEFR implementation strategies and/or procedures are shown to be successful? This was the main focus of this research: what do people say worked and did not work, with the reasons for success or lack of success.

4. What aspects do these successful strategies/procedures share, which could be recast in a generic $Q A$ frame? This informed the output from the project: Are the same points being made in both countries or are there major differences as a result of the two different contexts?

The QualiCEFR project used a multiphase mixed methods research design (Creswell \& Plano Clark, 2011) combining qualitative and quantitative research. First, qualitative data were collected through document searches and semi-structured interviews. Second, as a form of confirmation, quantitative data are being collected with an online survey - this step is ongoing. This type of mixed design is often used in program evaluation to support the development of a specific program (Creswell \& Plano Clark, 2011). The approach follows a design-based research paradigm, combining empirical research with a theory-driven design through collaboration between researchers and practitioners (Anderson \& Shattuck, 2012; van den Akker, Gravemeijer, McKenney, \& Nieveen, 2006).

Data collection and analysis were divided into five phases as illustrated in Figure 1. To date, the research team has completed Phases 1 to 3. In the following sections, each phase will be described in more detail. We then focus on the results from the analysis of the interviews conducted (Phases 2 and 3). 


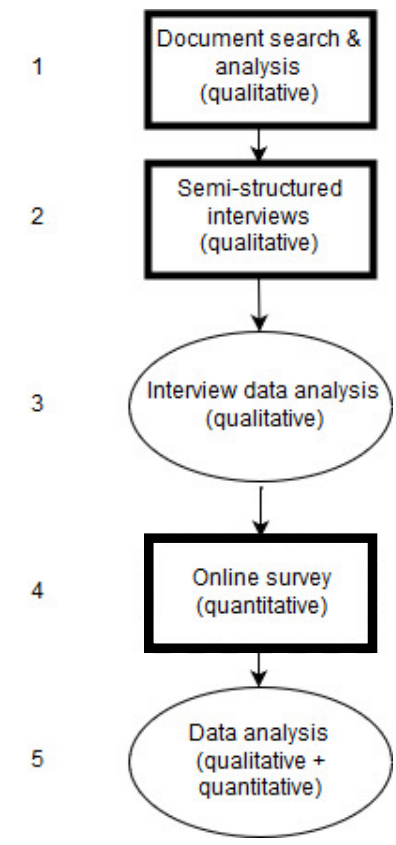

Figure 1. Data collection and analysis.

\section{Document Search and Analysis}

The first phase of the project consisted of a systematic search of published documents (online/hardcopy) from both Canada and Switzerland. The aim of this search was first to identify existing CEFR-implementation initiatives in order to gather qualitative data that would allow us to form a clear picture of the role and relevance (or lack of thereof) of the CEFR in second/foreign language education in both countries, and second to identify potential interview participants who had been involved in implementing the CEFR in their contexts.

The team analyzed Canadian documents dating from 2006, when the CEFR was first proposed in Canada (Vandergrift, 2006), and Swiss documents dating from 1991, the year when the intergovernmental CEFR Symposium took place there. These documents included curricula, development projects, classroom projects, textbooks, assessment procedures, and research articles written in one of the official languages (i.e., French and English) of the two countries. From the document analysis, a list of CEFR-related initiatives and projects was compiled, including information about the geographical and educational contexts in which such initiatives took place. In addition, during the document analysis, quality indicators of CEFR-related projects were identified. This analysis informed potential questions and QA indicators to be further investigated through the second phase of data collection: the semi-structured interviews.

\section{Semi-structured Interviews}

A total of 44 1-hour semi-structured interviews with stakeholders at the provincial or cantonal and national or federal levels both in Canada (28 interviews) and in Switzerland (16 interviews) were carried out during May and June 2016. To ensure a representative 
sample, criteria such as participants' roles, educational contexts, geographical areas, linguistic regions, and target languages taught were taken into account. Participants represented educational authorities, language associations, CEFR-related project developers, and public sector language education providers. Table 1 illustrates the participants' roles in their educational contexts.

Participants worked in a variety of Canadian provinces and Swiss cantons, which also correspond to different linguistic areas. In Canada, most participants worked in English-speaking areas (24 of 28), with a minority in Francophone areas (3 of 28) and one person in a bilingual area. In Switzerland, half of the stakeholders were located in Germanspeaking cantons ( 8 of 16), while the remaining half were distributed among French, Italian, and bilingual cantons. As shown in Table 2, in both countries the majority of participants were involved in French education (78.5\% in Canada and $68.75 \%$ in Switzerland).

Table 1

Number of Participants and Roles

\begin{tabular}{lcccccc}
\hline & Administrator & $\begin{array}{l}\text { Program } \\
\text { Coordinator/ } \\
\text { Director }\end{array}$ & $\begin{array}{l}\text { Teacher } \\
\text { Educator }\end{array}$ & Researcher & Teacher & Consultant \\
\hline Canada & 9 & 7 & 9 & 6 & 11 & 8 \\
Switzerland & 4 & 3 & 6 & 7 & 9 & 3 \\
\hline
\end{tabular}

Note. Some interviewees had more than one role, which explains why the numbers do not total 44 .

Table 2

Number of Participants (and Percentages) and Various Target Languages

\begin{tabular}{lllll}
\hline & $\begin{array}{l}\text { English } \\
(\%)\end{array}$ & $\begin{array}{l}\text { French } \\
(\%)\end{array}$ & $\begin{array}{l}\text { German } \\
(\%)\end{array}$ & $\begin{array}{l}\text { Other } \\
(\%)\end{array}$ \\
\hline Canada & $8(28.57)$ & $22(78.5)$ & $8(28.57)$ & $4(14.28)$ \\
Switzerland & $8(50)$ & $11(68.75)$ & $7(43.75)$ & $3(18.75)$ \\
\hline
\end{tabular}

The interview questions focused on the following areas:

1. role of the CEFR in the participants' contexts

2. specific initiatives and projects carried out to implement the CEFR

3. details about implementation procedures and strategies employed

4. presence or absence of QA elements during the implementation process

5. success/lack of success of the CEFR-related initiatives and response from the different parties involved, and

6. participants' advice.

The interviews were conducted either in person or via Skype and were audio-recorded. Subsequently, they were transcribed and member-checked. 


\section{Interview Data Analysis}

The third phase was the qualitative, thematic analysis of the data collected during the interviews. This analysis followed a multi-stage, iterative process that is explained in detail below.

Preliminary observations. First, immediately after conducting each interview round (one in Canada and one in Switzerland), preliminary observations of the most relevant and recurring themes, patterns and issues that emerged from the interviews were recorded. This preliminary analysis served two purposes: (a) to use the content of these observations as a basis to devise the thematic categories for the coding stage, and (b) to formulate initial hypotheses and identify apparent similarities and differences between the two countries that could be verified during the detailed analysis stage.

Thematic categories. The next step was to devise an initial set of categories that would be used to code the interview data. Some categories were selected deductively starting from the research questions and the theoretical framework of the study while others were formulated inductively starting from the patterns that were noticed in the data. The final list features 11 overarching categories, with each category including several subcategories (see Appendix 1).

Coding. Next, the interview data were coded with the draft thematic categories using the qualitative data analysis software NVivo. The coding team comprised three expert coders and two junior coders who initially carried out a test round of individual coding followed by discussion. Subsequently, the thematic categories were revised and more clearly defined and the coding process was organized in a spiral structure in which each cycle consisted of (a) independent coding, (b) checking and modifying the codes, and (c) refining and modifying the coding categories (see Figure 2). This process was employed for approximately one third of the data, until the list of thematic categories was finalized and all coders were familiar with the categories and the coding process itself. The two junior coders then independently coded the remaining data and each expert coder checked the codes related to a specific set of categories.

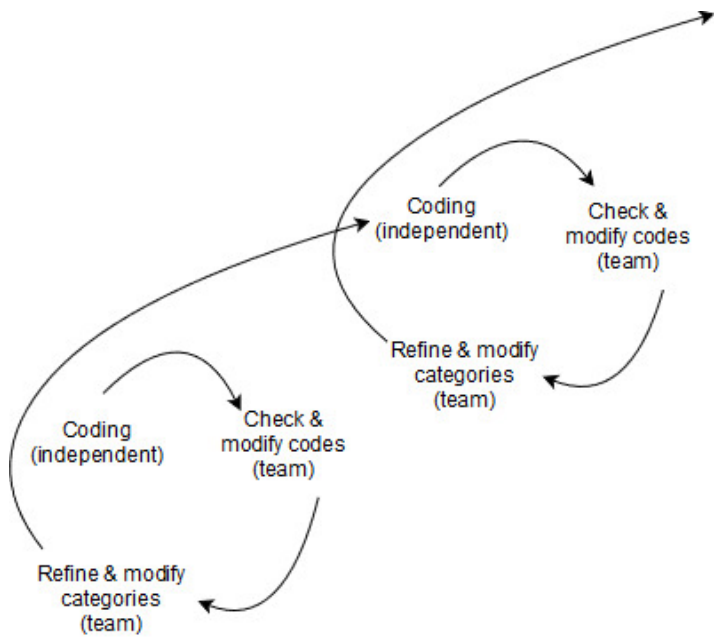

Figure 2. Coding cycles.

Canadian Journal of Applied Linguistics, Special Issue: 22, 1 (2019): 103-128 
Data analysis. Once all the interview data were coded on NVivo, they were analyzed to find relevant patterns and trends that would provide the answers to the research questions. To do this, the data set was prepared in two forms. In one form, each of the 44 interview transcripts was treated as a single source. In the other form, the comments by the respondents were divided according to the different projects and initiatives they had talked about, which gave a total of 121 projects. These 121 projects/initiatives that had been referred to in the interviews became the sources counted in the main analysis.

Different analysis techniques were employed depending on the specific research question explored. In this section we focus on the matrix query technique, which was the most commonly used, particularly to answer Research Question 3, What CEFR implementation strategies and/or procedures tend to be successful? Running a matrix query consists of cross-referencing the data coded under two specific categories or sets of categories to identify the links between the themes expressed by the two sets of categories. For instance, to find what implementation modalities were considered to have been a successful strategy as viewed by the interview respondents, a matrix query was run for all the categories referring to modalities employed (Set 1) and for those referring to success or lack thereof (Set 2). The QA procedures and the question of involvement and support were added to the modalities so as to include all aspects that might have been responsible for a successful or unsuccessful outcome. Table 3 shows the matrix query scheme with all the categories involved.

After running the matrix query, the table was filled with figures that indicated the number of text pieces coded under the selected categories.

Once a general idea of the situation was formed through the figures obtained from the query, a more in-depth analysis was performed by reading the specific pieces of text that were coded under the selected categories. For example, the 43 pieces of text in which teacher education was indicated as a successful strategy (See Table 3) were examined to investigate whether there were particular factors associated with this finding and/or to identify possible explanations for this occurrence. Information on the results obtained from the data analysis is provided in the Results section. 
Table 3

Matrix Query of Strategies Employed and Success or Lack of Success

\begin{tabular}{|c|c|c|}
\hline & $\begin{array}{c}\text { Successful } \\
\text { strategies used }\end{array}$ & $\begin{array}{r}\text { Unsuccessful } \\
\text { strategies used }\end{array}$ \\
\hline \multicolumn{3}{|l|}{ Modalities } \\
\hline Teacher Education & 43 & 17 \\
\hline Classroom trials & 10 & 0 \\
\hline External exams & 26 & 8 \\
\hline Collaborative groups & 23 & 6 \\
\hline Data collection & 10 & 3 \\
\hline Portfolios & 17 & 11 \\
\hline $\begin{array}{l}\text { Textbooks \& Pedagogical } \\
\text { material }\end{array}$ & 9 & 8 \\
\hline \multicolumn{3}{|l|}{ QA procedures } \\
\hline Planning & 20 & 4 \\
\hline Development & 23 & 2 \\
\hline Piloting & 17 & 1 \\
\hline Dissemination & 43 & 9 \\
\hline Evaluation & 18 & 4 \\
\hline Scientific Accompaniment & 15 & 2 \\
\hline \multicolumn{3}{|l|}{ Involvement \& Support } \\
\hline Teachers' involvement & 27 & 5 \\
\hline Administration's support & 16 & 2 \\
\hline
\end{tabular}

Data interpretation. An NVivo analysis is qualitative; the numbers in Table 3 reflect the number of occurrences of a particular code, or, as preferred in this study, the number of projects referred to in which the code in question appeared. Before discussing the research questions, it is interesting to see similarities and differences in aspects of the CEFR referred to in the two countries, as shown in Figure 3. 
CANADA

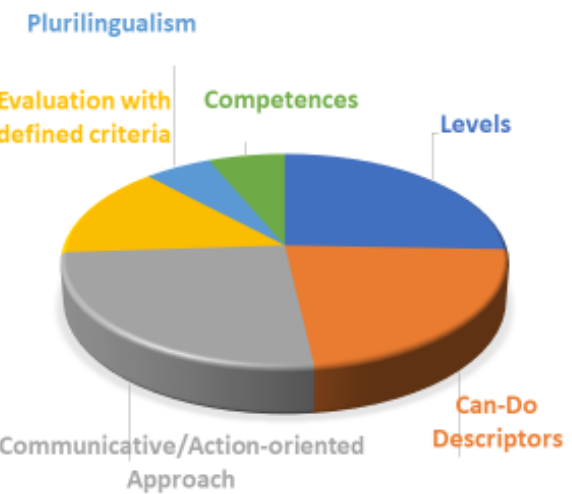

SWITZERLAND

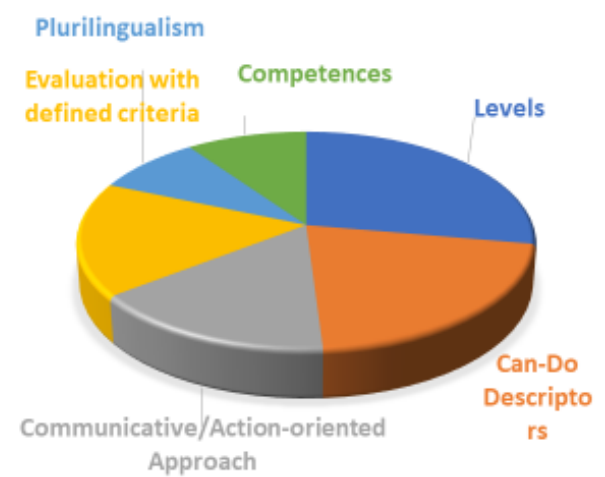

Figure 3. Aspects of the CEFR referred to.

Perhaps unsurprisingly, the proportion of references to levels and descriptors is virtually identical. The biggest difference is that whereas in Canada there is a higher proportion of references to the introduction of communicative and action-oriented tasks, in Switzerland there is more mention of evaluation with defined criteria and of a plurilingual approach.

\section{Results from the Interview Data}

Research Questions 1 and 3, were, as stated above, the main focus of this research:

1. What procedures were used to introduce CEFR implementation in different educational contexts in Canada and Switzerland?

3. What CEFR implementation strategies and/or procedures tend to be successful?

In other words, what strategies and procedures to introduce change through the CEFR, listed in Table 3, do people say worked or did not work, and to what extent were these same initiatives stated to have had a positive impact? Figures 4 and 5 show, for Switzerland and Canada respectively, the successful strategies identified and the QA procedures used, and to what extent these strategies and procedures were stated to have a positive impact. The length of the bars reflects the proportion of the 121 projects that had codings for the aspect concerned. Since this analysis is qualitative, it is the relative frequency of the occurrence of the different modalities and procedures that is of interest, not the actual numbers themselves. 


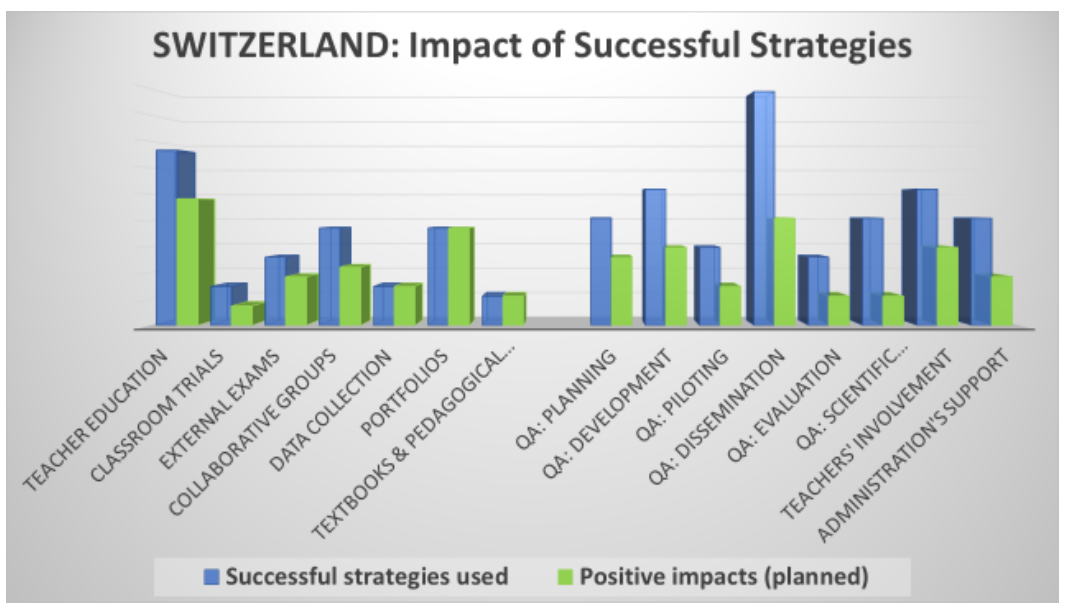

Figure 4. Impact of successful strategies and procedures: Switzerland.

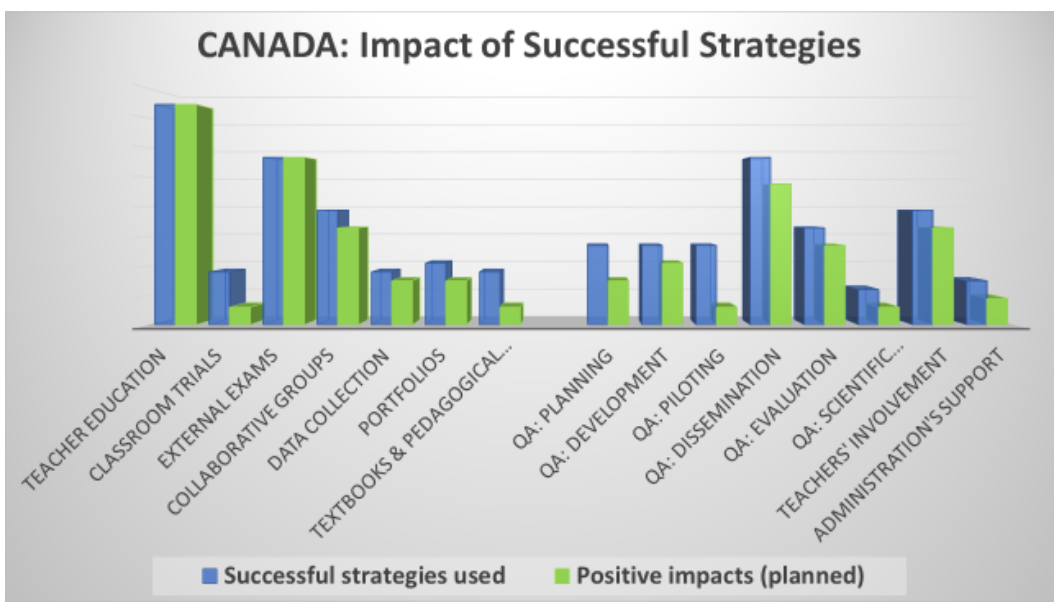

Figure 5. Impact of successful strategies and procedures: Canada.

As seen in Figures 4 and 5, the most frequently-cited successful modalities and procedures common to both countries appear to be teacher education, collaborative groups, dissemination procedures, and teacher involvement - all of which are in fact forms of engaging teachers in the initiative - and Portfolios. In Switzerland, 33\% of projects cited teacher education as a successful strategy, but only $24 \%$ explicitly mentioned a positive impact; for Canada, 37\% cited it as a successful strategy, clearly confirming a positive impact. With regard to collaborative groups, $19 \%$ in both Switzerland and Canada mentioned this as a successful strategy, with only $11 \%$ citing a positive impact in Switzerland and 16\% in Canada. Dissemination activities - understood as planned involvement in the project of teachers who will help spread the innovation as multiplierswas the most important strategy in Switzerland (44\%), with $20 \%$ explicitly reporting a positive impact, while in Canada the figures were $28 \%$ and $24 \%$ respectively. Finally, the Portfolio was cited as a vector in both countries, albeit at a lower level. While $10 \%$ in Canada cited them (7\% with a positive impact), the situation in Switzerland was more complicated. The same proportion, 19\%, cited Portfolios as a successful strategy as cited them as an unsuccessful strategy, with $17 \%$ confirming a positive impact. This contradiction reflects a certain "Portfolio fatigue" in Switzerland, since the instrument had been in use for over 15 years. 
Perhaps the biggest difference between the two contexts concerns the strategy of introducing an external CEFR-based examination (e.g., DELF) to create positive washback and pedagogical change. In Switzerland, the experience appeared to be mixed, as seen with the Portfolio; in Canada 28\% reported the implementation of the DELF as a positive strategy, explicitly citing a positive impact.

Space does not permit coverage of all of the findings, so we will focus on teacher education and the adoption of external examinations as two of the most important modalities, and will illustrate the key success factors of these two strategies. In each case, italics either in the main points or in short citations below indicate verbatim the participants' voices.

\section{Teacher Education}

It is not surprising that teacher education is the key factor in introducing any educational innovation. In relation to the CEFR, training programs may focus directly on aspects of the CEFR itself or may introduce it indirectly as in training on the DELF or another CEFR-based exam, a Portfolio, or a specific CEFR-based set of local resources (e.g., the Swiss Lingualevel for foreign languages, the Saskatchewan assessment toolkit for English language learners). What is interesting is the identification of aspects that make such teacher education more successful. Such successful strategies mentioned included the following:

a) Situating the training within and in relation to teachers' everyday realities and going at the teachers' pace. To achieve buy-in, it is important teachers feel that they have their experience and points of view acknowledged and feel they are part of the process:

- No or very little resistance from the instructors, because we took small steps, we respected their own pace of learning and their own views.

- Be careful of making assumptions about realities of the classroom; that's why I work with teachers in schools, 'cause they put me in my place and ground me in reality.

b) Giving a clear, evidence-based rationale as to why the changes are being introduced, preferably with some concrete evidence that they work:

- Help them to understand all aspects of WHY we are implementing the change (political, cultural, pedagogical).

- My strategy with instructors when something is being criticized is to respect their point of view and ask them: "You are telling me that this won't work. If you have some research, evidence, authors that back your point up, bring it to me and we'll discuss it. Because what I am presenting to you, I have my evidence and I presented it to you."

c) Involving large numbers of teachers early in the initiative in order to enable them to help shape it, take ownership of it, and act as both a support network for each other and as ambassadors for the project itself:

- One of the keys to the success of Lingualevel for example was the fact that a 
network of practitioners was established by training 188 teachers and getting them involved not only in implementing the resources but also participating in the development of the project.

d) Involving teachers as active participants through hands-on activities (e.g., projects, assignments, task forces) and not just as a captive audience at training events:

- In between workshop days teachers expected to do some practice, try out stuff and come back and discuss. . . Teachers asked to bring their tests and discuss them.

e) Providing practical, tangible tools that illustrate in practice the innovation concerned (e.g., sample tasks, assessment criteria grids, videos illustrating student performance at the different proficiency levels, with documentation showing how they meet the criteria for the level concerned):

- It's important to give instructors some concrete elements that will help them make the change in their practice.

- The criteria grid, the concreteness of providing the videos, the discussion of the videos in combination with the criteria-that's excellent practice.

f) Making the training a mandatory, ongoing series of linked activities spread out over a period of time (e.g., 2 to 3 months) with teachers trying things out with their classes - and networking.

- We're trying to generate a culture of cycles: things are going to be repeated over and over, it's an ongoing training.

\section{Adopting an External Exam}

The data from the respondents show that institutionalizing a CEFR-based external exam like the DELF led in many cases to:

a) Bringing better qualified teachers who become familiar with not just the exam but also with the CEFR approach; having a positive washback effect; spurring discussions, reflections, and collaboration among practitioners and significant changes in the curricula, teaching, and materials as teachers reflect on necessary changes to classroom pedagogy in order to help students achieve better results:

- The DELF is the catalyst, the vehicle of implementation of the CEFR, because once you get that up and happening, it trickles down to levels, instructional practices, etc.

b) Providing a clear implementation structure with available training materials tends to receive teachers' buy-in because teachers are directly involved, as they reflect on and improve their practices in collaborative and support groups:

- It has created a community of educators. Teachers come together for training, to correct the written examination, to do oral interviews in one another's classrooms. They support each other in their implementation. 
c) Providing a tangible objective and outcome that everybody (i.e., teachers, students, parents, administrators) understands and can relate to. The exam results provide concrete evidence of (a) students' proficiency and (b) the strengths and weaknesses of the program. Thus, this strategy tends to get buy-in all round and financial support:

- Since then we found it [the exam] a really valuable way of measuring the capacity of our program and keeping track of our students' language proficiency,

d) Bringing increased motivation and progress for students and teaching more targeted to strengths and weaknesses:

- The students' reaction shows that they have come to realize that French can be fun.

- The DELF is helping us: from the results, students are confident in the comprehension skills, but they are still weak in all the productions. The good news is teachers know that now and they are starting to work differently.

e) Changing the culture of assessment itself in a school, providing guidelines for tasks, assessment criteria and desired outcomes in terms of proficiency:

- Teachers had clearly in mind the objectives and grids, and they had to implement it in their teaching: they understood how to assess oral skills, while beforehand this concept didn't exist.

With respect to the second research question, Has a $Q A$ approach (or elements thereof) informed CEFR implementation?, Figures 4 and 5 show that, while being present, procedures associated with QA are not particularly prominent. The exception is the dissemination activities - the planning of which was considered to demonstrate a structured, QA approach. However, planning such activities could also easily be considered to be another teacher-focused implementation strategy (i.e., in our terms, a modality) rather than a quality assurance mechanism. Project evaluation-after a project - does appear in the findings for both countries (Switzerland: $13 \%$ with $6 \%$ positive impact; Canada: $16 \%$ with $13 \%$ positive impact). Formal project planning and scientific accompaniment appeared considerably stronger in Switzerland: $20 \%$ of projects for each as opposed to $13 \%$ and $6 \%$ respectively in Canada. However, there was some ambivalence about scientific accompaniment even in Switzerland, since only $6 \%$ stated that is had a positive impact. These two points are discussed in more detail below.

\section{Planning}

Some of the main points that emerged in the data analyzed in relation to planning are the following:

a) In the early stages, it is important to have a broad group of experts involved:

- ... if we were to advance the CEFR research and framework, in other words explore meaningfully the pedagogy attached to it, we needed to reach not only designated FSL, International languages, Native Languages 
Ministry person, but others as well who worked in other related branches at the Ministry.

b) Collaboration between big institutions - within or across national borders-seems to be effective in that it ensures a higher degree of trust and a shared vision:

- We established a CEFR provincial working board, started with nine boards and now all 60 boards are on it.

c) An initial needs analysis/evaluation phase helps determine both realistic goals and efficient development steps:

- You have to prepare the "terrain" [with teachers]. That's why our autoevaluation work was very important, because it prepared everyone. If you don't go through this type of quality assurance step, at least do something similar before moving and implementing the CEFR.

d) A combination in the planning of both a systematic top-down input from experts with support from institutions and bottom-up input from teachers helps ensure sustainable change:

- With DELF they used both a top-down and bottom-up approach: they involved the teachers who became DELF experts. . . In general it worked because teachers were involved; it was their project too.

e) Finally, since CEFR implementation is often a difficult process, one very important successful strategy is to have multiple entry points, which means carefully planning which entry points to work on and when and how to introduce them:

- If you want to have an impact, you need to have multiple entry points: One was the DELF . . The second was professional learning for teachers, changing instructional practices in the classroom ... A third way was implementing an in-between focus on classroom instruction and on the $D E L F$, almost a portfolio approach, where teachers were assessing kids' developing competences based on the levels, although not through an official certification.

\section{Scientific Accompaniment}

In scientific accompaniment, a small team of experts, often from universities, are charged with mapping out proposed stages in an overall project design. They will usually suggest milestones and quality assurance and monitoring procedures and may also play a role in training events. The main points to emerge here were that scientific accompaniment:

a) brings a new perspective and way of thinking and working that can complement that of administrators and practitioners and provide an element of quality assurance:

- Important to have more communication between administration and specialists, bring together the different focuses and the different linguistics regions. 
- Don't work alone: [. . .] important to do a pluridisciplinary work, work with experts in the different fields: people who bring the field experience.

b) can build trust with both administrators and teachers since academics are not following their own agenda, and the stakeholders see and appreciate that:

- One key element is trust. People from the cantons and federal offices trust XX and their team because they do not sell anything. . . There are good relationships of trust and respect with the CDIP (la Conférence suisse des directeurs cantonaux de l'instruction publique).

- $X$ 's tendency to "think things through" may be instrumental in building trust with stakeholders... The fact that $X$ and $Y$ see themselves as learners within these projects is a key to the success.

\section{Discussion}

The implementation strategies on which we have reported above-teacher education and introducing external exams - are just two of the modalities for using the CEFR to introduce innovation in language education. As mentioned above, based on the participants' responses it seems important to have multiple approaches, rather than seeing one single tool or technique as a panacea. Nevertheless, as the voice of the participants shows, both these modalities appear to offer a high leverage effect for improving the quality of language teaching and learning, as also suggested by some reports (e.g., CMEC, 2015; Rehner, 2014) as well as Moonen et al. (2013). However, many respondents emphasized that, regardless of the implementation modalities selected, it is essential to adopt a combination of a topdown and a bottom-up development approach, having people working in all positions of the system involved, and to allow enough time to introduce change. Development does not happen overnight, and any significant change requires long term planning over several years, as in the Ontario initiatives referred to earlier in this article. Initiatives that are purely bottom-up originating from teachers appear to fizzle out if not nourished and supported officially; on the other hand, attempts to achieve change using a top-down approach by decree (e.g., by providing every school with portfolios for every student, or by just changing textbooks, as was done in Switzerland) run into opposition unless the initiative is carried by a significant number of teachers who have been able to give input into the development. These findings echo the factors related to teachers' involvement in educational change listed by van den Branden (2009) and Moonen et al. (2013), particularly the need for time for experimentation paired with the concrete exemplification and feasibility of what innovation entails. Many respondents emphasized that a successful CEFR-based innovation tends to be one in which all stakeholders have been involved in a medium term action plan: it "has to be full-on" and "Everyone needs to see themselves in this picture." The need for management involvement to organize an ongoing training programme was also emphasized by Moonen et al. (2013). Thus, we join Arnott et al. (2017) in calling for "ongoing conversations encouraging stakeholders to consider how they might take up pan-Canadian interests with respect to various aspects of the CEFR and its related tools" (p. 48).

Several of the points outlined in the results section might appear to be common sense. However, as the percentages displayed suggest, not a single one of them, nor of the 
other modalities investigated, was followed by a majority of the projects outlined in the interviews. The fact that teacher education is the main vehicle for CEFR integration is not new, but a 2016 survey of Council of Europe member states in relation to the new descriptors included in the CEFR Companion Volume (Council of Europe, 2018) revealed that even in Europe only $50 \%$ of member states integrated the CEFR systematically into initial teacher education. In Canada, the situation seems no better; participants at the 2014 discussion forum reported that: "integration of an explicit and in-depth study of the CEFR (i.e., its philosophy and pedagogical concepts) had hardly ever been observed in ITE [initial teacher education] programs" (Arnott et al., 2017, p. 40).

For reasons of space, we have focused on teacher education, the adoption of external examinations, and the significance of systematic planning and scientific accompaniment. There are more chances that an initiative will be successful if all stakeholders are involved, if there are multiple entry points to the CEFR, and if there is ongoing, long-term professional development to provide the necessary support for practitioners, as suggested by the 2014 St. Catharines discussion (see Arnott et al., 2017 and CMEC, 2015). This is not to say that other routes may not be successful. However, as suggested in the discussion of Figure 4, experience with the ELP appears to be two-edged. The CEFR is in fact often (con)fused with the ELP and its simple off-the-shelf checklists, with reference sometimes being made to the "the CEFR and the ELP" as a fixed phrase (e.g., Kristmanson et al., 2011) when it is clear from the context that it is the ELP that is being discussed, not the CEFR itself. There appears to be a similar tendency to conflate the DELF and CEFR, although those behind successful Canadian DELF-based innovation emphasize that DELF introduction should be accompanied by intensive training in the CEFR and action-oriented approach. The problem with such indirect approaches to CEFR implementation is that its core messages and holistic perspective can get lost, resulting in a superficial familiarity with it (Díez-Bedmar \& Byram, 2018). Awareness of this problem informed the decision to include, in the newly released CEFR Companion Volume with New Descriptors (Council of Europe, 2018), a text that explains in plain language the key features of the CEFR.

A related issue is that CEFR implementation is not always integrated into an official assessment and grading system, which may remain purely normative, as with the Ontario curriculum (Ontario Ministry of Education, 2014). As both van den Branden (2009) and Graves (2008) pointed out, in a change towards competence-based language teaching, formal assessment needs to be changed accordingly. Assessment in relation to CEFRbased, defined proficiency criteria appears to be more common in Switzerland (see Figure 2), anchored through the HarmoS national standards and Lingualevel resources. This alignment of planning, teaching, and assessment appears, from the data collected, to be less prevalent in Canada, where initiatives still tend to be focused on a particular product or technique (e.g., DELF, Portfolio).

Finally, although there are in fact noticeable differences between responses from Canada and from Switzerland, particularly in relation to the use of an examination as a catalyst, as shown in Figures 4 and 5, virtually every major point reported in the results section was made by respondents from both countries. This is encouraging in relation to the final research question: What aspects do these successful strategies/procedures share, which could be recast in a generic QA frame? Obviously, as with the CEFR itself and the body of materials surrounding it, any generic tool needs to be adapted and customized to a given context, but it does appear that there may be a common basis for advisory guidelines. 
The purpose of the final data collection stage of the QualiCEFR project - the survey-is to double check the extent to which there is consensus on the relative importance of the most significant points raised.

\section{Conclusion}

The CEFR has a complex vision of language learning (Piccardo \& North, 2019), as underlined in the recent CEFR Companion Volume (Council of Europe, 2018). Innovation in education is itself a complex, developmental process over time: simple/istic solutions and quick fixes do not work and there is no silver bullet. The adoption of a QA perspective can help to make such complexity manageable, to see the forest as well as the trees. In its final phase, QualiCEFR is developing an advisory document that presents the main findings in guidance notes. This document could enhance greater coherence between planning, teaching, and assessment, as well as to support the shift in pedagogy towards an actionoriented approach.

The results of the QualiCEFR study are being fed into a sister project: "A Quality Assurance Matrix for CEFR Use" (QualiMatrix), which forms part of the 2016-19 programme of the European Centre for Modern Languages (ECML). QualiMatrix operationalizes the concept of a quality cycle (Deming, 1986) in a coherent spiral of planning, implementation/enactment, and evaluation (Graves, 2008), such alignment being perhaps the main message of the CEFR for language programme planning (North, Angelova, Jarocsz, \& Rossner, 2018). The Matrix itself is a heuristic, online tool with quality indicators, recommendations, a collection of promising practices, and links to relevant resources. It can be used by stakeholders to inform CEFR implementation at the levels of policy, curriculum development, teaching, and assessment.

The QualiCEFR and QualiMatrix projects are intended to make a modest contribution to the adoption of a principled, QA approach to curriculum innovation in language education, particularly in contexts where a customised QA scheme is not available. As Moonen et al. (2013) suggested, CEFR innovation often starts as the initiative of individual teachers who after a while manage to convince their department and management to adopt the CEFR. Thus, by providing individual innovators with a structured tool based upon QA principles that are familiar to managers and administrators, we hope to facilitate and boost the innovation cycle.

Correspondence should be addressed to Enrica Piccardo.

Email: enrica.piccardo@utoronto.ca

\section{Note}

${ }^{1}$ Data have shown that $15.8 \%$ of Canadians and over $23 \%$ of Swiss most often speak a heritage language at home (Statistics Canada, 2016; Swiss Federal Statistics, 2017).

\section{Relevant Websites}

CEFR: https://www.coe.int/en/web/common-european-framework-referencelanguages/home

DELF: http://www.ciep.fr/en/delf-dalf 
Lingualevel: http://www.lingualevel.ch

QualiMatrix: https://www.ecml.at/ECML-Programme/Programme20162019/QualityassuranceandimplementationoftheCEFR/Introduction/tabid/3094/Defa ult.aspx

Saskatchewan assessment toolkit: https://www.saskatchewan.ca/government/educationand-child-care-facility-administration/services-for-school-administrators/supportsfor-english-as-an-additional-language

\section{References}

Anderson, T., \& Shattuck, J. (2012). Design-based research: A decade of progress in education research? Educational Researcher, 41(1), 16-25.

Arnott, S., Brogden, L. M., Faez, F., Peguret, M., Piccardo, E., Rehner, K., Taylor, S. K., \& Wernicke, M. (2017). The Common European Framework of Reference for Languages (CEFR) in Canada: A research agenda. Canadian Journal of Applied Linguistics, 20(1), 31-54.

Beaudoin, M. (2010). European language portfolio in whole-school use. Institute for Innovation in Second Language Education: Edmonton, Canada.

Biggs, J., \& Tang, C. (2011). Teaching for quality learning at university. Maidenhead, United Kingdom: McGraw-Hill and Open University Press.

Byram, M., \& Parmenter, L. (Eds.). (2012). The Common European Framework of Reference: The globalisation of language policy. Bristol, United Kingdom: Multilingual Matters.

Conseil atlantique des ministres de l'Éducation et de la Formation (CAMET). (2010). La littératie: une clé d'apprentissage et une voie vers la prospérité - Plan d'action 2009-2014 pour le Canada atlantique. Retrieved from http://cametcamef.ca/images/eng/docs/2010\%20Literacy\%20Progress $\% 20$ Report $\% 20$ FRANCA IS\%20FINAL.pdf

Council of Europe. (1992). Transparency and coherence in language learning in Europe: Objectives, assessment and certification. Symposium held in Rüschlikon, 10-16 November 1991. Strasbourg, France: Council for Cultural Co-operation.

Council of Europe. (2001). Common European Framework of Reference for Languages: Learning, teaching, assessment. Cambridge, United Kingdom: Cambridge University Press.

Council of Europe. (2018). Common European framework of reference for languages: learning, teaching, assessment-Companion volume with new descriptors. Strasbourg, France: Council of Europe Publishing. Retrieved from https://www.coe.int/en/web/common-european-framework-referencelanguages

Council of Ministers of Education, Canada (CMEC). (2010). Working with the Common European Framework of Reference for Languages (CEFR) in the Canadian context: Guide for policy-makers and curriculum designers. Retrieved from https://www.cmec.ca/docs/assessment/CEFR-canadian-context.pdf

Council of Ministers of Education, Canada (CMEC). (2015). French as a second language in Canada: Potential for collaboration. Retrieved from https:/cmec.ca/Publications/Lists/Publications/Attachments/370/CASLT-Report- 
FSL-in-Canada-EN.pdf

Creswell, J. W., \& Plano Clark, V. L. (2011). Designing and conducting mixed methods research. ( $2^{\text {nd }}$ ed.). Thousand Oaks, CA: Sage.

Deming, W.E. (1986). Out of the crisis. Cambridge, United Kingdom: Cambridge University Press.

Dickinson, D. K. (2011). Teachers' language practices and academic outcomes of preschool children, Science, 333(6045), 964-967.

Díez-Bedmar, M. B., \& Byram, M. (2018): The current influence of the CEFR in secondary education: teachers' perceptions. Language, Culture and Curriculum. doi:10.1080/07908318.2018.1493492.

Eaquals. (2008). CEFR curriculum case studies: Examples from different contexts of implementing "Can do" descriptors from the Common European Framework of Reference. Retrieved from https://www.eaquals.org/wp-content/uploads/EaqualsCEFR-Curriculum-Case-Studies.pdf

EDK. (1998). Sprachenkonzept Schweiz: Welche Sprachen sollen die Schülerinnen und Schüler der Schweiz während der obligatorischen Schulzeit lernen? Bericht einer von der Kommission für allgemeine Bildung eingesetzten Expertengruppe Gesamptsprachenkonzept. Bern, Germany: EDK (Schweizerische Konferenz der kantonalen Erziehungsdirektoren), 15 Juli 1998.

EDK. (2004). Sprachenunterricht in der obligatorischen Schule: Strategie der EDK und Arbeitsplan für die gesamtschweizerische Koordination von 25. März 2014 (Beschluss der EDK Plenarsammlung). Bern, Germany: EDK (Schweizerische Konferenz der kantonalen Erziehungsdirektoren). Retrieved from https://edudoc.ch/record/30008/files/Sprachen_d.pdf

Faez, F., Majhanovich, S., Taylor, S. K., Smith, M., \& Crowley, K. (2011). The power of "Can do" statements: Teachers' perceptions of CEFR-informed instruction in French as a second language classrooms in Ontario. Canadian Journal of Applied Linguistics, 14(2), 1-19.

Faez, F., Taylor, S. K., Majhanovich, S., Brown, P., \& Smith, M. (2011). Teachers' reactions to CEFR's task-based approach for FSL classrooms. Synergies Europe, 6, 109-120.

Figueras, N. (2012). The impact of the CEFR. English Language Teaching Journal, 66(4), $77-485$.

Figueras, N. (2013). The CEFR in Catalonia: The perceptions of the users. In N. Figueras (Ed.), The impact of the CEFR in Catalonia (pp. 25-39). Barcelona, Spain: Barcelona APAC Monographs.

Gamse, B. C., Bloom, H. S., Kemple, J. J., \& Jacob, R. T. (2008). Reading first impact study: Interim report. NCEE 2008-4016, ERIC Number: ED501218

Graves, K. (2008). The language curriculum: A social contextual perspective. Language Teaching, 41(2), 147-181.

Hawkey, R. (2006). Impact theory and practice: Studies of the IELTS test and Progetto Lingue 2000. Studies in Language Testing, 24. Cambridge, United Kingdom: Cambridge University Press.

Heyworth, F. (2013). Applications of quality management in language education. Language Teaching, 48(3), 281-315.

Jones, N., \& Saville, N. (2009). European language policy: Assessment, learning and the CEFR. Annual Review of Applied Linguistics, 29, 51-63. 
Kiely, R., \& Rea-Dickins, P. (2005). Program evaluation in language education. London, United Kingdom: Palgrave Macmillan.

Kristmanson, P., Lafargue, C., \& Culligan, K. (2011). From action to insight: A professional learning community's experiences with the European Language Portfolio. Canadian Journal of Applied Linguistics, 14(2), 53-67.

Lenz, P. (2007). HarmoS FS —-Bildungsstandards für den Fremdsprachenunterricht: Auftrag Vorgehen-Ergebnisse. Babylonia, 4, 24-29.

Lions-Olivieri, M.-L., \& Liria, P. (Eds.). (2009). L'approche actionnelle dans l'enseignement des langues. Douze articles pour mieux comprendre et faire le point. Paris, France: Difusión-Maison des langues.

Majhanovich, S., Faez, F., Smith, M., Taylor, S. K., \& Vandergrift, L. (2010). Describing FSL language competencies: The CEFR within an Ontario context. Unpublished manuscript, Western University, London, Canada.

Martyniuk, W., \& Noijons, J. (2007, February) Executive summary of results of a survey on the use of the CEFR at national level in the Council of Europe Member States. Paper presented at the intergovernmental Language Policy Forum "The Common European Framework of Reference for Languages (CEFR) and the development of language policies: challenges and responsibilities," Strasbourg, France.

Matheidesz, M. (2010). International accreditation of quality in language learning and teaching. University of Cambridge ESOL - Research Notes, 39, 33-39.

Mison, S., \& Jang, I. C. (2011). Canadian FSL teachers' assessment practices and needs: implications for the adoption of the CEFR in a Canadian context. Synergies Europe, 6, 99-108.

Moonen, M., Stoutjesdijk, E., de Graaf, R., \& Corda, A. (2013). Implementing CEFR in secondary education: Impact on FL teachers' educational and assessment practice. International Journal of Applied Linguistics 23(2), 226-246. doi:10.1111/ijal.12000

Muresan, L., Heyworth, F. Mateva, G., \& Rose, M. (2007). Qualitraining: A training guide for quality assurance in language education. Strasbourg, France: Council of Europe.

North, B. (1995). The development of a common framework scale of descriptors of language proficiency based on a theory of measurement. System, 23, 445-465.

North, B. (2000). The development of a common framework scale of language proficiency. New York, NY: Peter Lang.

North, B. (2010). The educational and social impact of the CEFR. In L. Taylor \& C. Weir (Eds.), Language testing matters: Investigating the wider social and educational impact of assessment - Proceedings of the ALTE Cambridge Conference, April 2008 (pp. 357-377). Studies in Language Testing Series, 31. Cambridge, United Kingdom: Cambridge University Press.

North, B., Angelova, M., Jarocsz, E., \& Rossner, R. (2018). Language course planning. Oxford, United Kingdom: Oxford University Press.

North, B., \& Schneider, G. (1998). Scaling descriptors for language proficiency scales. Language Testing, 15(2), 217-262.

Ontario Ministry of Education. (2013). The Ontario curriculum 2013 French as a second language core French grades 4-8, extended French grades 4-8, French immersion grades 1-8. Retrieved from http://www.edu.gov.on.ca/eng/curriculum/elementary/fsl18-2013curr.pdf

Ontario Ministry of Education. (2014). The Ontario curriculum grades 9 to 12. French as a 
second language core French, extended French, French immersion. Retrieved from http://www.edu.gov.on.ca/eng/curriculum/secondary/fs1912curr2014.pdf

Ottawa-Carleton District School Board. (2010). Grade 12 proficiency test: Spring 2010 pilot project (Technical report). Ottawa, Canada.

Ottawa-Carleton District School Board. (2011). Grade 12 proficiency test: Results from 2010-2011 administration (Technical report). Ottawa, Canada.

Piccardo, E. (Ed.). (2006) La richesse de la diversité : recherches et réflexions dans l'Europe des langues et des cultures [The richness of diversity: Research and reflections in the Europe of languages and cultures]. Synergies Europe, 1. Retreived from http://ressources-cla.univ-fcomte.fr/gerflint/Europe1/europe1.html

Piccardo, E. (2013). (Re)conceptualiser l'enseignement d'une langue seconde à l'aide d'outils d'évaluations: comment les enseignants canadiens perçoivent le CECR. The Canadian Modern Language Review/La Revue Canadienne des langues vivantes, 69(4), 386-414.

Piccardo, E., \& North, B. (2019). The action-oriented approach: a dynamic vision of language education. Bristol, United Kingdom: Multilingual Matters.

Puren, C. (2002). Perspectives actionnelles et perspectives culturelles en didactique des langues-cultures : vers une perspective co-actionnelle co-culturelle. Les langues modernes, 3, 55-71.

Puren, C. (2009) La nouvelle perspective actionnelle et ses implications sur la conception des manuels de langue. In M.-L. Lions-Olivieri \& P. Liria (Eds.), L'approche actionnelle dans l'enseignement des langues (pp. 119-137). Barcelona, Spain: Difusión, Centre de recherche et de publication des langues.

Ramseier, E., Moser, U., Moreau, J., \& Antonietti, J.-P. (2008). Schlussbericht der HarmoS-Methodologiegruppe. EDK (Schweizerische Konferenz der kantonalen Erziehungsdirektoren). Berne, Germany. Retrieved from http://www.lehrplanforschung.ch/wp-content/uploads/2011/06/MethodologieSchlussbericht-_HarmoS1.pdf

Rea-Dickins, P., \& Scott, C. (2007). Washback from language tests on teaching, learning and policy: Evidence from diverse settings. Assessment in Education, 14(1), 1-7.

Rehner, K. (2014). French as a second language (FSL) student proficiency and confidence: Pilot project 2013-2014: A report of findings. Project funded by the Government of Ontario and the Government of Canada through the Department of Canadian Heritage and directed by Curriculum Services Canada.

Rehorick, S., \& Lafargue, C. (2005). The European language portfolio and its potential for Canada (Proceedings of a conference held at UNB). Retrieved from http://www.unbf.ca/ L2/Resources/PDFs/ELP/UNB_ELP fullreport.pdf

Richards, J. C. (2013). Curriculum approaches in language teaching: Forward, central and backwards design. RELC Journal, 44(1) 5-33.

Saskatchewan Ministry of Education. (2013). A guide to using the Common Framework of Reference (CEFR) with learners of English as an additional language. Retrieved from http://publications.gov.sk.ca/documents/11/82934A\%20Guide\%20to\%20Using\%20the\%20CFR\%20with\%20EAL\%20Learners.pdf

Schneider, G., \& North, B. (2000). Fremdsprachen können - was heisst das? Skalen zur Beschreibung, Beurteilung und Selbsteinschätzung der fremdsprachlichen Kommunikationsfähigkeit. Chur/Zürich, Switzerland: Nationales Forschungsprogramm 33: Wirksamkeit unserer Bildungssysteme, Verlag Rüegger. 
Statistics Canada. (2016). Language highlight tables, 2016 Census. Retrieved from: http://www12.statcan.gc.ca/census-recensement/2016/rt-td/lang-eng.cfm

Stoicheva, M., Hughes, G., \& Speitz, H. (2009, September/October). The European language portfolio: An impact study. Paper presented at the 8th International Seminar on the European Language Portfolio, Council of Europe, Strasbourg, France.

Swiss Federal Statistics. (2017). Langues les plus fréquentes parlées habituellement à la maison par la population résidente permanente âgée de 15 ans ou plus. Retrieved from https://www.bfs.admin.ch/bfs/fr/home/statistiques/population/languesreligions.assetdetail.2263148.html

Takala, S. (2013). The CEFR in use: Some observations of three Nordic countries. In N. Figueras (Ed.), The impact of the CEFR in Catalonia. APAC Monographs, 9 (pp. 918). Girona, Spain: APAC.

Tang, M. (2010). Le DELF et l'avenir de l'apprentissage du français en Colombie Britannique. Le Journal de l'immersion, 32(2), 20-24.

Tardif, C., \& Fortin-Duplessis, S. (2015). Aiming Higher: Increasing bilingualism of our Canadian youth. Report of the Standing Senate Committee on Official Languages. Retrieved from https:/sencanada.ca/content/sen/committee/412/ollo/rep/rep06jun15-e.pdf

van den Akker, J., Gravemeijer, K., McKenney, S., \& Nieveen, N. (2006). Educational design research. London, United Kingdom: Routledge.

van den Branden, K. (2009). Diffusion and implementation of innovations. In M. Long \& C. Doughty (Eds.), The handbook of language teaching (pp. 659-672). Malden, MA: Blackwell.

Vandergrift, L. (2006). New Canadian perspectives: Proposal for a common framework of reference for languages in Canada. Ottawa, Canada: Department of Canadian Heritage / Patrimoine canadien. Retrieved from http://publications.gc.ca/collections/collection_2011/pc-ch/CH4-114-2006-eng.pdf

Wall, D. (2012). Washback in language assessment. In C. A. Chapelle (Ed.), The Encyclopedia of Applied Linguistics. doi:10.1002/9781405198431.wbeal1274 


\section{Appendix: Analysis Categories}

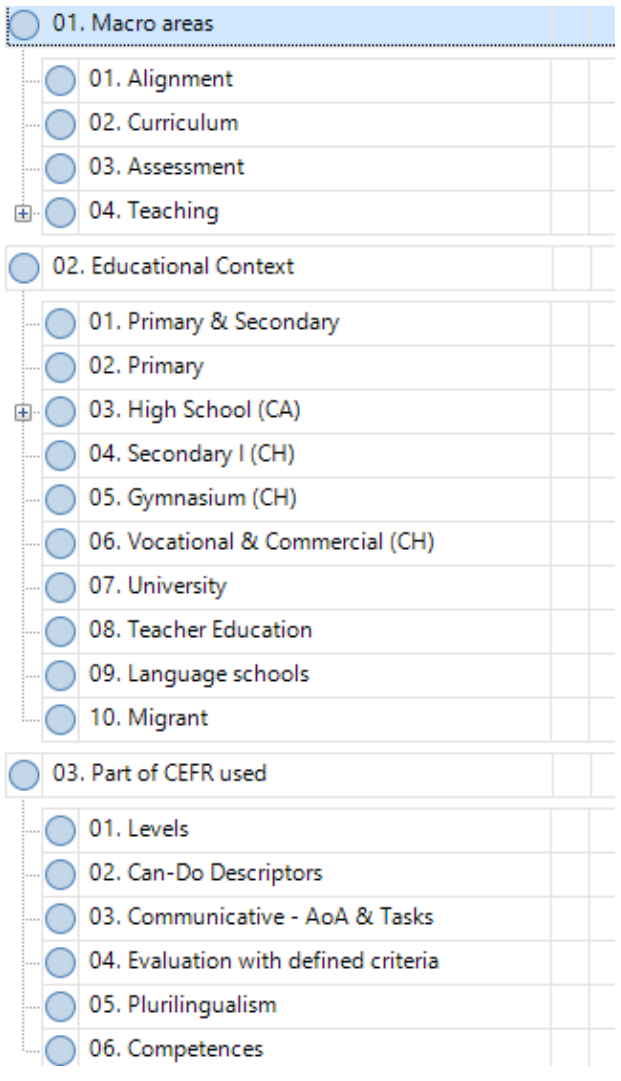

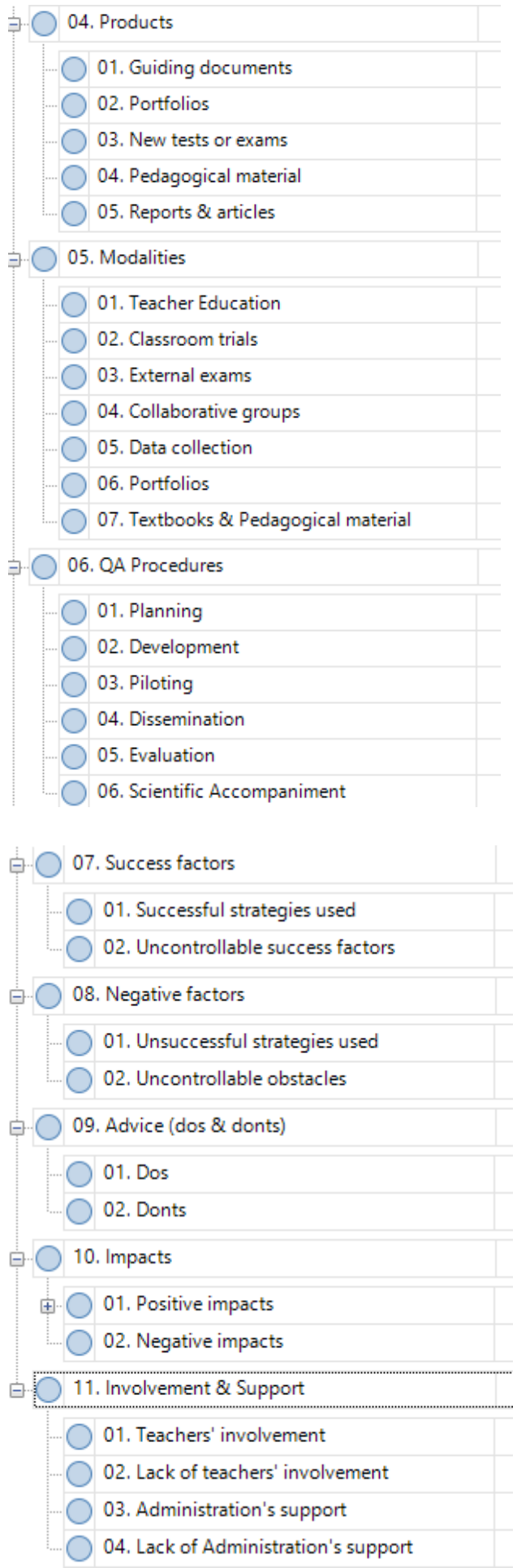

